\title{
Prevalence of depressive symptoms in patients with rheumatoid arthritis at a regional hospital in KwaZulu-Natal, South Africa
}

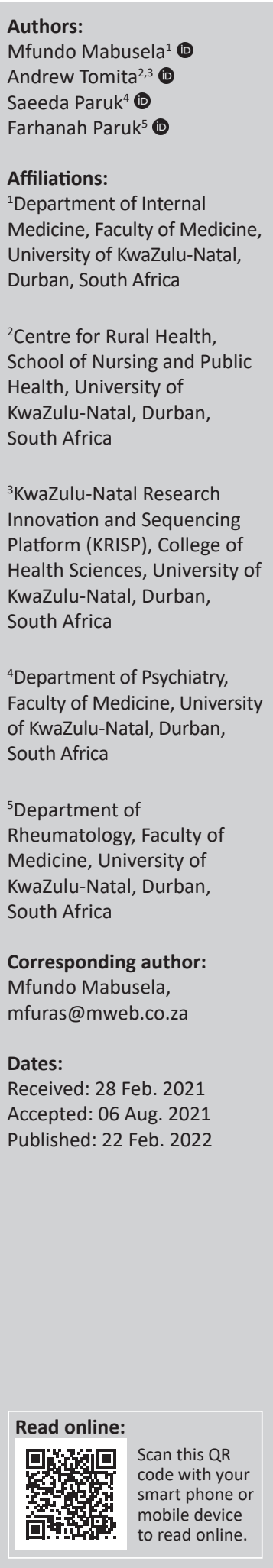

Background: Depression affects $14.8 \%-38.8 \%$ of patients with rheumatoid arthritis (RA) in developed countries. The prevalence and risk factors for depression in patients with RA in sub-Saharan Africa is not well established.

Aim: To determine the prevalence of depressive symptoms in patients with RA.

Setting: Public sector regional hospital in South Africa.

Methods: A cross-sectional descriptive study was undertaken with 110 adult RA patients. A structured socio-demographic and clinical questionnaire, the modified health assessment questionnaire (mHAQ), the simplified disease activity index (SDAI) for RA, the patient health questionnaire (PHQ-9), and the Household Food Insecurity Access scale (HFIAS) for nutritional status, were used. Correlates of depressive symptomatology in participants with RA were identified using $t$-tests and regression analyses.

Results: Most of the participants were women (90.9\%), 67\% had moderate to severe RA disease on the SDAI score, $92.7 \%$ reported functional disability (HAQ score of $\geq 1$ ), and $87.2 \%$ reported mild to severe depressive symptoms. Unemployment $(p<0.01)$, severe food insecurity $(p<0.01)$ and functional disability $(p=0.02)$, were significantly associated with the depressive symptoms, but not with disease activity $(p=0.8)$ or inflammatory markers $(p=0.63)$. Unemployment (adjusted $\beta=-5.07, p<0.01$ ) and severe food insecurity (adjusted $\beta=-4.47$, $p<0.01$ ) were significantly associated with depressive symptoms, based on the adjusted regression model.

Conclusion: As RA effects functional status, with the impact of the resulting unemployment and food insecurity being associated with depression, affected people should be screened for depression and managed using a multidisciplinary approach, especially considering the role of social determinants in RA patients with depression.

Keywords: rheumatoid arthritis; disease activity; depression; functional impairment; food insecurity.

\section{Introduction}

Untreated rheumatoid arthritis (RA) is associated with increased morbidity, mortality and poorer quality of life. ${ }^{1,2}$ Studies show that more than a third of formerly working persons are no longer able to perform work after 5 years of being diagnosed with RA, with this proportion increasing to more than $50 \%$ after 10 years. ${ }^{3}$ Affected persons not only have to find alternative sources of income, if possible, but are also often not able to perform their routine daily tasks and activities, which can result in inactivity, ${ }^{4}$ dependence on others and depression.

Depression is more common in persons with RA than in the general population, being estimated to affect $14.8 \%-38.8 \%$ of those suffering from RA. ${ }^{5}$ Depressed persons with RA have poorer longterm outcomes, including pain, a higher number of comorbidities ${ }^{6}$ and increased mortality rates. ${ }^{7}$ The pathogenesis of depression in RA is not fully understood, however, it is postulated that immune dysregulation secondary to depression may play a central role in triggering the condition. ${ }^{8}$ The reticulo-limbic structures in the brain, which regulate pain and emotions, may also contribute to ongoing inflammation. ${ }^{9}$

How to cite this article: Mabusela M, Tomita A, ParukS, Paruk F. Prevalence of depressive symptoms in patients with rheumatoid arthritis at a regional hospital in KwaZulu-Natal, South Africa. S Afr J Psychiat. 2022;28(0), a1702. https://doi.org/10.4102/sajpsychiatry.v28i0.1702 Copyright: @ 2022. The Authors. Licensee: AOSIS. This work is licensed under the Creative Commons Attribution License. 
Comorbid depression in RA is associated with a worsening of disease activity and severity, ${ }^{10}$ and has a significant impact on patient quality of life. ${ }^{11}$ Recent studies have shown a positive correlation between pain and depressive symptoms in RA. ${ }^{12,13}$ The condition impacts negatively on depression, and affected persons may experience perseverative thoughts, which is the process of uncontrolled repetitive negative thinking that results from the stress of their disease activity. ${ }^{14}$

There are limited studies on the prevalence and risk factors for depression amongst people with RA in Africa. Apart from high RA disease activity, which was identified in a Pakistani study, ${ }^{15}$ a small Tunisian study found that the main predictors associated with depression in RA patients were: female gender, absence of professional activity or social support, poor quality of life, and underlying structural joint damage. ${ }^{16}$ An Egyptian study showed that RA patients had significantly higher depression scores, were more likely to be clinically depressed compared to osteoarthritis patients, and were identified as being single and having a higher functional disability, when assessed by the health assessment questionnaire (HAQ), as significant predictors of clinical depression. ${ }^{17} \mathrm{~A}$ more recent observational cross-sectional study from Egypt involving 200 RA patients found that $42 \%$ had moderate to severe depression on the patient health questionnaire (PHQ-9) score, which correlated with age, disease duration, joint deformities, and inflammatory markers: C-reactive protein (CRP) and erythrocyte sedimentation rate (ESR). ${ }^{18}$

Solomon et al., in a study in Gauteng province, South Africa (SA), showed that in low-to-middle income countries (LMIC), such as SA, RA patients experienced substantially more depressive symptoms than those from developed countries, independent of age, sex, ethnic origin and disease characteristics. ${ }^{19}$ The potential impact of social circumstances, such as food insecurity and unemployment, were not explored in the study, although the authors postulated that social factors play an important role.

Although the association between food insecurity and depressive symptoms has not been explored amongst RA patients, a study from KwaZulu-Natal (KZN) province found that major depression was significantly associated with household food insecurity in patients with multi-drug resistance tuberculosis. ${ }^{20}$ Food insufficiency is associated with increased psychiatric morbidity, ${ }^{21}$ with a longitudinal study in the United States of America (US) reporting a simultaneous causal relationship between food insecurity and depression in a sample of rural, low-income women. ${ }^{22}$ Developing countries generally have higher rates of food insecurity because of poor socio-economic status. In addition, food insecure individuals tend to have inadequate management of chronic disease as a result of limited access to healthcare and or low health literacy or education attainment, even when controlled for education and income. ${ }^{23,24}$

Although many factors contribute to depression, unemployment has been consistently associated with higher rates in adults. ${ }^{25,26} \mathrm{~A}$ Lithuanian cross-sectional study found that long-term unemployment was associated with a higher likelihood of a depressed mood over a 12-month period. ${ }^{27}$ A study conducted in the US amongst young healthy adults aged 18 to 25 years, showed higher rates of depression in those unemployed (23\%) than in those employed (12\%). ${ }^{28}$

There are limited studies from developing countries about the prevalence and association of depressive symptoms in people living with RA. There are also few studies about the effects of social factors, such as unemployment, on depression in SA. This study will assist in improving the understanding of the association between depressive symptoms and RA, as well as predisposing clinical and social risk factors.

\section{Method}

A cross-sectional, descriptive study of outpatients with RA attending a specialist arthritis clinic at King Edward VIII Hospital, a regional hospital in Durban, KZN province, was conducted from February to October 2019. The hospital services the urban and peri-urban areas of the eThekwini Municipality and offers specialist rheumatology and psychiatric services, amongst others. Patients seen are mainly black people and Indian (the second largest group), this demographic profile being reflected in our study cohort. According to the Census South Africa 2011, KZN had a population of 10.2 million people which comprises Africans $(86.7 \%)$ followed by Indians/Asians $(7.4 \%)^{29}$. Adult patients who were 18 years and older, diagnosed with RA, as per the American College of Rheumatology (ACR) criteria of $1987^{30}$ or 2010 ACR/European League Against Rheumatism (EULAR) criteria, ${ }^{31}$ on treatment for RA for at least 6 months, able and willing to consent for the study, and able to communicate in English or in isiZulu were randomly enrolled. Three patients refused to participate because of time constraint. Patients who were less than 18 years old, not willing to participate or unable to give informed consent, who had overlap syndromes and/or other auto-immune diseases and/or other inflammatory arthritis, were excluded.

\section{Measures}

A structured questionnaire was used to collect demographic details (age, gender, ethnicity, marital status, educational level, and household monthly income) and clinical data, which was verified from the clinical records. Weight, height, smoking, human immunodeficiency virus (HIV) status, comorbid diseases, RA disease duration, serology, extra-articular manifestations, $x$-ray changes, RA disease activity scores and inflammatory markers were extracted from the clinical file. The inflammatory markers recorded were measured on the day of clinic visit. Body mass index (BMI) was classified according to the World Health Organization (WHO) classification. ${ }^{32}$ All selfreported questionnaires were available in English and isiZulu, with the interviews being conducted by the primary investigator (PI) who is bilingual, with the aid of a trained research assistant.

The modified HAQ (mHAQ), which is a patient reported tool, was used to measure both health status and healthrelated quality of life. ${ }^{33}$ The mHAQ tool is regarded as the 
gold standard for measuring physical disability in RA patients. $^{34}$ It is a 20-item questionnaire that covers most activities of daily living (ADL) in eight domains, with score ranges from 0 , indicating no disability, to a maximum of three, indicating dependence on others for all ADL. The mHAQ score is well validated for use in clinical care and correlates well with disease activity, ${ }^{33}$ having been used in other South African RA studies. ${ }^{35,36}$

Rheumatoid arthritis disease activity was measured using the simplified disease activity index (SDAI), which is a good predictor of joint damage and physical disability and widely used as an outcome measure. ${ }^{37}$ The score is a numerical summation of five outcome parameters: tender and swollen joint count (based on a 28-joint assessment), patient and physician global assessment of disease activity [visual analogue scale (VAS) $0-10 \mathrm{~cm}$ ] and level of CRP $(\mathrm{mg} / \mathrm{dL}$, normal $<1 \mathrm{mg} / \mathrm{dL}$ ). A SDAI score of $<3.3$ indicates remission, 3.4-11.0 low disease activity, 11.1-26.0 moderate disease activity, and $\geq 26.1$ high disease activity, and correlates RA disease activity with progression of joint damage. ${ }^{38}$ It has been validated by the South African Rheumatism and Arthritis Association, for scoring disease activity in RA, ${ }^{39}$ and has been used previously in the country. ${ }^{40}$

Depressive symptoms were assessed using the PHQ-9 tool, which has been validated for use in SA to identify comorbid depression in patients with chronic conditions. ${ }^{41,42}$ Depression was graded according to the PHQ-9 scores as follows: $<5$ no depression; 5-10 mild depression; 11-14 moderate depression and $>15$ severe depression.

All participants identified with symptomatic depression were referred to the psychiatric unit for further evaluation.

The Household Food Insecurity Access scale (HFIAS) version 3 was used to measure food insecurity. ${ }^{43}$ The tool consists of a culturally invariant set of nine questions covering three related domains related to food insecurity and has been a widely used in KZN. ${ }^{44,45,46}$

The CRP within the last month, serology [rheumatoid factor (RF) and anti-citrullinated protein antibody (ACPA)] and HIV results were extracted from the patient records.

\section{Statistical analysis}

Three analyses were conducted for this investigation, the first being the socio-demographic and clinical characteristics, which were summarised using proportions (\%) for categorical and mean (and standard deviation-SD) for continuous variables. Second, we compared depressive symptomatology level by socio-demographic and clinical characteristics using a $t$-test. Third, we identified socio-demographic and clinical covariates of depressive symptomatology based on regression models. Given the small sample size, covariates found to be significant from the second analyses were fitted to the regression model, with all statistical analyses being performed using STATA 16.

\section{Ethical considerations}

Ethical approval to conduct the study was obtained from the Biomedical Research Ethics Committee of the University of KwaZulu-Natal, (BE622/18), the hospital and the provincial Department of Health. The study was conducted according to the ethical guidelines and principles of the International Declaration of Helsinki and Guidelines for Good Clinical Practice in the Conduct of Clinical Trials with Human Participants in South Africa.

\section{Results}

\section{Socio-demographic and clinical profile}

Of the 113 patients with RA who were approached to participate 110 were enrolled, with a mean age of 56.6 years (SD \pm 11.9 years), their socio-demographic profile and clinical characteristics are indicated in Table 1 . The majority of the participants were female $(n=100,90.9 \%)$, unemployed $(n=96,87.3 \%)$ and reported severe food insecurity $(n=63,57.3 \%)$.

The disease activity, as per the SDAI score, functional status (HAQ) and serology (RF and ACPA), are shown in Table 2. The majority of participants $(n=74,67 \%)$ had moderate to severe disease, according to their SDAI scores, and a total of 102 participants $(92.7 \%)$ also reported severe functional disability, with a HAQ score of 1 or greater. An elevated CRP

TABLE 1: Socio-demographic and clinical characteristics of 110 participants with rheumatoid arthritis.

\begin{tabular}{|c|c|c|}
\hline \multirow[t]{2}{*}{ Characteristics } & \multicolumn{2}{|c|}{ Total } \\
\hline & $n$ & $\%$ \\
\hline \multicolumn{3}{|l|}{ Age category (years): } \\
\hline $25-45$ & 15 & 13.6 \\
\hline $46-59$ & 46 & 41.8 \\
\hline $60+$ & 49 & 44.5 \\
\hline \multicolumn{3}{|l|}{ Gender: } \\
\hline Female & 100 & 90.9 \\
\hline \multicolumn{3}{|l|}{ Ethnicity: } \\
\hline Black people & 61 & 55.5 \\
\hline Indian & 36 & 32.5 \\
\hline White people & 8 & 7.3 \\
\hline Mixed race & 5 & 4.5 \\
\hline \multicolumn{3}{|l|}{ BMI categories $\left(\mathrm{kg} / \mathrm{m}^{2}\right)$ : } \\
\hline Normal & 29 & 26.4 \\
\hline Overweight & 37 & 33.6 \\
\hline Obese & 44 & 40 \\
\hline \multicolumn{3}{|l|}{ Marital status: } \\
\hline Single/divorced/widowed & 40 & 36.4 \\
\hline \multicolumn{3}{|l|}{ Employment: } \\
\hline Yes & 14 & 12.7 \\
\hline \multicolumn{3}{|l|}{ Current smoking: } \\
\hline Yes & 15 & 13.6 \\
\hline \multicolumn{3}{|l|}{ Food insecurity: } \\
\hline None to moderate & 47 & 42.7 \\
\hline Severe food insecurity & 63 & 57.3 \\
\hline \multicolumn{3}{|l|}{ Comorbidities: } \\
\hline Yes & 59 & 53.6 \\
\hline \multicolumn{3}{|l|}{ HIV infection: } \\
\hline Positive & 8 & 7.3 \\
\hline
\end{tabular}

BMI, body mass index; HIV, human immunodeficiency virus. 
TABLE 2: Rheumatoid arthritis disease activity profile in rheumatoid arthritis participants.

\begin{tabular}{|c|c|c|}
\hline \multirow[t]{2}{*}{ Characteristics } & \multicolumn{2}{|c|}{ Total } \\
\hline & $N$ & $\%$ \\
\hline \multicolumn{3}{|c|}{ Simplified disease activity score (SDAI): } \\
\hline Low disease activity $(\leq 11)$ & 36 & 32.7 \\
\hline Moderate (12-26) & 49 & 44.6 \\
\hline Severe $(\geq 27)$ & 25 & 22.7 \\
\hline \multicolumn{3}{|l|}{ Functional status (HAQ): } \\
\hline Normal functioning $(<1)$ & 8 & 7.3 \\
\hline Impaired functioning $(\geq 1.1)$ & 102 & 92.7 \\
\hline \multicolumn{3}{|l|}{ Depression (PHQ-9 score): } \\
\hline Less than mild $(\leq 4.9)$ & 14 & 12.7 \\
\hline Mild (5 - 10.9) & 21 & 19.1 \\
\hline Moderate $(11-14.9)$ & 28 & 25.5 \\
\hline Severe symptomatology ( $\geq 15$ ) & 47 & 42.7 \\
\hline \multicolumn{3}{|l|}{ Extra articular features: } \\
\hline Yes & 24 & 21.8 \\
\hline \multicolumn{3}{|l|}{ Rheumatoid Factor: } \\
\hline Positive & 87 & 79.1 \\
\hline \multicolumn{3}{|l|}{ ACPA: } \\
\hline Positive & 86 & 78.2 \\
\hline \multicolumn{3}{|l|}{ C-reactive protein: } \\
\hline Normal $(\leq 10.9)$ & 64 & 58.2 \\
\hline Elevated ( $\geq 11$ ) & 46 & 41.8 \\
\hline \multicolumn{3}{|l|}{ X-ray erosive disease: } \\
\hline Present & 49 & 44.6 \\
\hline \multicolumn{3}{|l|}{ DMARDS: } \\
\hline One & 54 & 47.3 \\
\hline Two & 46 & 41.8 \\
\hline Three & 10 & 9.1 \\
\hline
\end{tabular}

$\mathrm{HAQ}$, health assessment questionnaire; ACPA, anti citrullinated peptide antibody; DMARDS, disease modifying anti-rheumatic drugs.

TABLE 3: Association of depression symptomatology by socio-demographic data in rheumatoid arthritis participants.

\begin{tabular}{|c|c|c|c|c|c|}
\hline \multirow[t]{2}{*}{ Socio-demographics } & \multicolumn{2}{|c|}{$\begin{array}{c}\text { Depression } \\
\text { symptomatology }\end{array}$} & \multicolumn{3}{|c|}{$\begin{array}{l}\text { Statistical } \\
\text { result }\end{array}$} \\
\hline & Mean & SD & $t$ & $d f$ & $p$ \\
\hline \multicolumn{6}{|l|}{ Age category (years): } \\
\hline $25-45$ & 11.3 & 5.2 & $F=0.48$ & 2,107 & 0.62 \\
\hline $46-59$ & 13.1 & 6.2 & - & - & - \\
\hline $60+$ & 12.5 & 6.5 & - & - & - \\
\hline \multicolumn{6}{|l|}{ Gender: } \\
\hline Male & 12.2 & 3.5 & -0.22 & 108 & 0.82 \\
\hline Female & 12.7 & 6.4 & - & - & - \\
\hline \multicolumn{6}{|l|}{ Ethnicity: } \\
\hline Black & 13.5 & 5.9 & $F=1.26$ & 2,107 & 0.29 \\
\hline Indian & 11.6 & 6.4 & - & - & - \\
\hline Mixed race/White & 11.5 & 7.0 & - & - & - \\
\hline \multicolumn{6}{|l|}{ Marital Status: } \\
\hline Single/divorced/widowed & 12.2 & 6.0 & -0.5 & 108 & 0.62 \\
\hline Married & 12.8 & 6.4 & - & - & - \\
\hline \multicolumn{6}{|l|}{ Employed: } \\
\hline No & 13.4 & 5.9 & 3.79 & 108 & $<0.01$ \\
\hline Yes & 7.1 & 5.3 & - & - & - \\
\hline \multicolumn{6}{|l|}{ Social Support: } \\
\hline No & 13.6 & 6.7 & 1.41 & 108 & 0.16 \\
\hline Yes & 11.9 & 5.9 & - & - & - \\
\hline \multicolumn{6}{|l|}{ Food Insecurity: } \\
\hline None to moderate & 9.4 & 6.3 & -5.17 & 108 & $<0.01$ \\
\hline Severe food insecurity & 15 & 5.0 & - & - & - \\
\hline
\end{tabular}

was found in $46(41.8 \%)$ participants. Extra-articular manifestations were present in $24(21.8 \%)$ participants and consisted of: anaemia $(n=15,13.6 \%)$, osteoporosis $(n=5$, $4.5 \%)$, interstitial lung disease $(n=2,1.8 \%)$, Sjogren's syndrome $(n=1,0.9 \%)$ and uveitis $(n=1,0.9 \%)$. Erosive disease on radiographs was seen in $49(44.6 \%)$ patients, and all participants were on disease modifying anti-rheumatic drugs (DMARDS), and 59 (53.6\%) were on two or more DMARDS.

\section{Depressive symptoms and socio-demographic and clinical features}

Overall, 96 (87.2\%) participants reported mild to severe depressive symptoms (score of 5 or more on PHQ 9). Tables 3 and 4 summarise the level of depressive symptoms based on the socio-demographic (Table 3) and clinical (Table 4)

TABLE 4: Association of depression symptomatology by clinical characteristics.

\begin{tabular}{|c|c|c|c|c|c|}
\hline \multirow[t]{2}{*}{ Clinical characteristics } & \multicolumn{2}{|c|}{$\begin{array}{c}\text { Depression } \\
\text { symptomatology }\end{array}$} & \multicolumn{3}{|c|}{ Statistics } \\
\hline & Mean & SD & $t$ & $d f$ & $p$ \\
\hline \multicolumn{6}{|c|}{ Body mass categories $\left(\mathrm{kg} / \mathrm{m}^{2}\right)$ : } \\
\hline Normal & 13 & 6.1 & $F=0.08$ & 2,107 & 0.92 \\
\hline Overweight & 12.4 & 6.3 & - & - & - \\
\hline Obese & 12.6 & 6.4 & - & - & - \\
\hline \multicolumn{6}{|l|}{ Currently smoking: } \\
\hline No & 12.8 & 6.2 & 0.95 & 108 & 0.34 \\
\hline Yes & 11.2 & 6.6 & - & - & - \\
\hline \multicolumn{6}{|l|}{ HIV status: } \\
\hline Negative & 12.4 & 6.3 & -1.49 & 108 & 0.14 \\
\hline Positive & 15.8 & 3.9 & - & - & - \\
\hline \multicolumn{6}{|l|}{ Comorbidities: } \\
\hline No & 12.1 & 5.6 & -0.85 & 108 & 0.4 \\
\hline Yes & 13.1 & 6.7 & - & - & - \\
\hline \multicolumn{6}{|l|}{ Extra articular features: } \\
\hline No & 12.6 & 6.1 & 0.07 & 108 & 0.95 \\
\hline Yes & 12.5 & 6.8 & - & - & - \\
\hline \multicolumn{6}{|l|}{ Functional Status (HAQ): } \\
\hline Normal function $(<1)$ & 7.8 & 5.4 & -2.34 & 108 & 0.02 \\
\hline Low functional $(\geq 1)$ & 13 & 6.1 & - & - & - \\
\hline \multicolumn{6}{|l|}{ Disease activity (SDAI): } \\
\hline None to low $(\leq 11)$ & 10.7 & 6.4 & -0.25 & 108 & 0.8 \\
\hline Moderate (12-26) & 13.4 & 6.2 & - & - & - \\
\hline Severe $(\geq 27)$ & 13.9 & 5.6 & - & - & - \\
\hline \multicolumn{6}{|c|}{ C-Reactive Protein Level (CRP): } \\
\hline Normal $(\leq 10)$ & 12.9 & 5.98 & 0.48 & 108 & 0.63 \\
\hline Severe $(\geq 11)$ & 12.3 & 6.58 & - & - & - \\
\hline \multicolumn{6}{|l|}{ Rheumatoid factor: } \\
\hline Negative & 12.6 & 6.18 & -0.05 & 108 & 0.96 \\
\hline Positive & 12.6 & 6.26 & - & - & - \\
\hline \multicolumn{6}{|c|}{ Anti-citrullinated peptide antibody: } \\
\hline Negative & 12.3 & 6.15 & -0.25 & 108 & 0.8 \\
\hline Positive & 12.7 & 6.26 & - & - & - \\
\hline \multicolumn{6}{|l|}{ X-ray erosive disease: } \\
\hline No abnormality & 12.2 & 6.28 & -0.82 & 108 & 0.41 \\
\hline Abnormal & 13.2 & 6.15 & - & - & - \\
\hline \multicolumn{6}{|l|}{ Medication: } \\
\hline None or one & 12.9 & 5.72 & 0.44 & 108 & 0.66 \\
\hline Two or more & 12.4 & 6.65 & - & - & - \\
\hline Obese & 12.6 & 6.39 & - & - & - \\
\hline
\end{tabular}

HIV, human immunodeficiency virus. 
characteristics. The bivariate analysis based on the $t$-test shows that employment $(p<0.01)$, severe food insecurity $(p<0.01)$ and functional disability (HAQ score of $\geq 1$ ), (p 0.02) were significantly associated with depressive symptom scores on the PHQ-9. There was no association between depressive symptom score and disease activity $(p=0.8)$ or CRP $(p=0.63)$. Unemployment (adjusted $\beta=-5.07, p<0.01$ ) and severe food insecurity (adjusted $\beta=-4.47, p<0.01$ ) were the only significant covariates associated with the depressive symptom scores, based on the adjusted regression model (model 1). When model 1 was controlled for basic socio-demographic variables, such as sex and gender, the significance of the finding did not change (model 2).

\section{Discussion}

This is the first study to describe the prevalence and association of depressive symptoms and food insecurity in patients with established RA. The main study findings are that there was a high prevalence of depressive symptoms in patients with RA, and that these were associated with unemployment $(p<0.01)$, severe food insecurity $(p<0.01)$, and impaired functional level [HAQ score 1 or more] $(p<0.02)$. However, the logistic regression showed that only unemployment and severe food insecurity were associated with depressive symptoms, and that there was no association with any clinical variables of RA, including CRP levels.

The prevalence of depression in this study was $87.3 \%$, which was significantly above the 12-month prevalence of $4.5 \%$ reported for the general population in the South African Stress and Health Study (SASH), ${ }^{47}$ and greater than the prevalence of $38 \%$ reported in a meta-analysis reviewing 72 studies that included 13189 patients living with RA. ${ }^{5}$ The rate was also higher than the $18 \%$ and $30 \%$ prevalence reported for minor depression or dysthymic disorder, respectively, in RA patients in a Chinese systemic review. ${ }^{48}$ The prevalence rate also exceeded studies from Tunisia and Egypt, which were $45 \%{ }^{17}$ and $42 \%,{ }^{19}$ respectively. The use of different methods or tools to estimate depression prevalence may account for the differences observed.

An earlier study by Solomon et al. in South African RA patients also found a higher burden of depression in the public than private sector using the Arthritis Impact Depression Scale (AIMS) screening tool.$^{20}$ The high prevalence rate reported in this study was may be because of the use of a screening rather than a diagnostic tool, overlap between depressive and RA somatic symptoms, or subjective over reporting by participants. However, the results suggest the urgent need for inclusion of mental health screening services for this population.

Solomon's study also suggested that depression was more common in RA patients in LMIC than previously thought, and postulated that social circumstances and comorbidities may play an important role in predicting depression in this cohort. $^{21}$ The finding of depressive symptoms being associated with unemployment in this study is consistent with those reported elsewhere $28,46,49$ in people living with RA. The majority of the patients who participated in our study had low socio-economic circumstances and education levels. ${ }^{50}$ Unemployment in patients with RA is significantly affected by the stage and duration of RA, and increases with disease duration; ${ }^{3}$ our findings suggests that this may drive their depressive symptom development.

In this study, $57.3 \%$ of patients also reported severe food insecurity, which was associated with depressive symptoms, the two being strongly associated in low-income areas. ${ }^{51,52}$ This finding highlights that social factors may increase depression risk, ${ }^{53}$ which then impacts on treatment adherence and quality of life, as seen in other chronic disorders, such as HIV infection. ${ }^{54}$

This study, similar to other cross-sectional and retrospective studies conducted previously in Africa, including in SA, ${ }^{20,36}$ also supported the finding that there was a high level of RA disease activity and functional disability amongst people living with the condition. Having difficulty performing functional tasks was associated with a higher occurrence of depressive symptoms amongst Chinese middle aged and older adults ${ }^{55}$ and in a Pakistani study. ${ }^{56}$ In this study, the majority of patients had functional impairment, with the bivariate analysis suggesting that their functional level was associated with depressive scores similar to other studies. ${ }^{17,18}$ However, it was not significant on logistic regression, indicating the need to further explore this in a larger study.

Although most of the patients had moderate to severe disease activity, based on their SDAI score, erosive disease and raised CRP, these were not associated with depressive symptoms. In contrast, in the Tunisian study, the main predictors for depression in RA patients were high RA disease activity, impaired quality of life and existence of structural change. ${ }^{17}$ Similarly, an Egyptian study also found significant positive correlations between hospital anxiety depression scaledepression subscale (HADS-D) and age, disease duration, HAQ score, visual analogous scale for pain, RA Disease Activity Score-28 (DAS 28) and CRP levels. ${ }^{19}$ The lack of association between depression and functional impairment, disease activity scores, inflammatory markers or radiological changes in this study may be because of social factors driving the condition in this LMIC setting, where patients receive specialist medical level care but are negatively affected by economic challenges. The findings suggest that adverse socio-economic factors may be relevant in depressive symptom risk, as indicated in the study by Solomon et al. ${ }^{20}$

\section{Limitations}

This is a single centre urban hospital-based study, with a small sample size of outpatients treated in a public health sector arthritis clinic, thus limiting the generalisability of findings to other settings. This could result in a bias of the results towards variables affected by poor socio-economic circumstances, for example food insecurity. 


\section{Conclusions}

The high prevalence of depressive symptoms amongst the patients with RA is concerning, and the association with unemployment and severe food insecurity suggests the need for regular depression screening, as well as the need to address social issues at chronic medical outpatient services. The study findings highlight the need to consider psychosocial and clinical factors that may influence health outcomes, and hence the need to develop more integrated services that includes a multidisciplinary management approach with medical, mental health and social work services. Larger, multicentre, longitudinal quantitative and qualitative studies are needed to better understand the factors associated with depressive symptoms in this clinical population.

\section{Acknowledgements}

The authors would like to acknowledge Slindile Prudence Dlamini for her assistance with data collection.

\section{Competing interests}

The authors declare that they have no financial or personal relationships that may have inappropriately influenced them in writing this article.

\section{Authors' contributions}

F.P. conceptualised and assisted with the development and writing up of the protocol and the manuscript. S.P. assisted with the study design, protocol writing up and editing of the manuscript. A.T. assisted with protocol and the statistical analysis, and writing up of the manuscript. M.M. contributed to the development of protocol, conducting the study and the writing of the manuscript.

\section{Funding information}

This research received no specific grant from any funding agency in the public, commercial or not-for-profit sectors.

\section{Data availability}

The data that supports the findings of this study are available on request from M.M., the corresponding author.

\section{Disclaimer}

The views and opinions expressed in this article are those of the authors, and do not necessarily reflect the official policy or position of the institution or any affiliated agency of the authors.

\section{References}

1. Cobb S, Anderson F, Bauer W. Length of life and cause of death in rheumatoid arthritis. N Engl J Med. 1953;249(14):553-556. https://doi.org/10.1056/NEJM 195310012491402

2. Allebeck P. Increased mortality in rheumatoid arthritis. Scand J Rheumatol. 1982;11(2):81-86. https://doi.org/10.3109/03009748209098167

3. Yelin E, Meenan R, Nevitt M, Epstein W. Work disability in rheumatoid arthritis: Effects of disease, social, and work factors. Ann lintern Med. 1980;93(4):551-556. https://doi.org/10.3109/03009748209098167
4. Barrett E, Scott D, Wiles N, Symmons D. The impact of rheumatoid arthritis on employment status in the early years of disease: A UK community-based study. Rheumatology. 2000;39(12):1403-1409. https://doi.org/10.1093/rheumatology/ 39.12.1403

5. Matcham F, Rayner L, Steer S, Hotopf M. The prevalence of depression in rheumatoid arthritis: A systematic review and meta-analysis: reply. Rheumatology (Oxford, England). 2014;53(3):578-579. https://doi.org/10.1093/rheumatology/ket439

6. Katz PP, Yelin EH. Prevalence and correlates of depressive symptoms among persons with rheumatoid arthritis. J Rheumatol. 1993;20(5):790-796.

7. Ang DC, Choi $\mathrm{H}$, Kroenke $\mathrm{K}$, Wolfe $\mathrm{F}$. Comorbid depression is an independent risk factor for mortality in patients with rheumatoid arthritis. I Rheumatol. 2005;32(6):1013-1019.

8. Maes M, Bosmans E, De Jongh R, Kenis G, Vandoolaeghe E, Neels H. Increased serum IL- 6 and IL-1 receptor antagonist concentrations in major depression and treatment resistant depression. Cytokine. 1997;9(11):853-858. https://doi. org/10.1006/cyto.1997.0238

9. Parker JC, Wright GE. The implications of depression for pain and disability in rheumatoid arthritis. Arth Rheum Off J Am Coll Rheumatol. 1995;8(4):279-283. rheumatoid arthritis. Arth Rheum Off J Am
https://doi.org/10.1002/art.1790080412

10. Sunar I, GariP Y, Yilmaz Ö, Bodur H, Ataman S. Disease activity (rheumatoid arthritis disease activity index-5) in patients with rheumatoid arthritis and its association with quality of life, pain, fatigue, and functional and psychological association with quality of life, pain, fatigue,
status. Arch Rheumatol. 2015;30(2):144-149.

11. Matcham F, Scott IC, Rayner L, et al. The impact of rheumatoid arthritis on qualityof-life assessed using the SF-36: A systematic review and meta-analysis. Sem Arth Rheum. 2014;44(2):123-130. https://doi.org/10.1016/j.semarthrit.2014.05.001

12. Nakajima A, Kamitsuji S, Saito A, et al. Disability and patient's appraisal of general health contribute to depressed mood in rheumatoid arthritis in a large clinical study in Japan. Modern Rheumatol. 2006;16(3):151-157. https://doi.org/ 10.3109/s10165-006-0475-5

13. Cadena J, Vinaccia S, Pérez A, Rico MI, Hinojosa R, Anaya J-M. The impact of disease activity on the quality of life, mental health status, and family dysfunction in colombian patients with rheumatoid arthritis. J Clin Rheumatol. 2003;9(3): 142-150. https://doi.org/10.1097/01.RHU.0000073434.59752.f3

14. Ruscio AM, Seitchik AE, Gentes EL, Jones JD, Hallion LS. Perseverative thought: $A$ robust predictor of response to emotional challenge in generalized anxiety disorder and major depressive disorder. Behav Res Ther. 2011;49(12):867-874. https://doi.org/10.1016/j.brat.2011.10.001

15. Imran MY, Khan SEA, Ahmad NM, Raja SF, Saeed MA, Haider II. Depression in rheumatoid arthritis and its relation to disease activity. Pak J Med Sci. 2015;31(2):393-397.

16. Tekaya R, Saadi F, Mahmoud I, et al. [Assessment of depression in rheumatoid arthritis: A cross sectional study on 60 patients]. Presse Med (Paris, France: 1983). 2012;41(5):e220-e225. https://doi.org/10.1016/j.lpm.2011.10.029

17. Abdel-Nasser A, Abd El-Azim S, Taal E, El-Badawy S, Rasker J, Valkenburg H. Depression and depressive symptoms in rheumatoid arthritis patients: An analysis of their occurrence and determinants. Br J Rheumatol. 1998;37(4):391-397. https://doi.org/10.1093/rheumatology/37.4.391

18. ISherbiny DA, Saad WE. Depression in rheumatoid arthritis patients: Screening for a frequent yet underestimated comorbidity. Egyptian Rheumatol. 2020;42(2): 89-93. https://doi.org/10.1016/j.ejr.2019.07.002

19. Solomon A, Christian BF, Woodiwiss AJ, Norton GR, Dessein PH. Burden of depressive symptoms in South African public healthcare patients with established rheumatoid arthritis: A case-control study. Clin Exp Rheumatol. 2011;29(3): 506-512.

20. Tomita A, Ramlall S, Naidu T, Mthembu SS, Padayatchi N, Burns JK. Major depression and household food insecurity among individuals with multidrugresistant tuberculosis (MDR-TB) in South Africa. Soc Psychiatry Psychiat Epidemiol. 2019;54(3):387-393. https://doi.org/10.1007/s00127-019-01669-y

21. Muldoon K, Duff P, Fielden S, Anema A. Food insufficiency is associated with psychiatric morbidity in a nationally representative study of mental illness among food insecure Canadians. Soc Psychiatry Psychiatr Epidemiol. 2013;48(5): 795-803. https://doi.org/10.1007/s00127-012-0597-3

22. Huddleston-Casas C, Charnigo R, Simmons LA. Food insecurity and maternal depression in rural, low-income families: A longitudinal investigation. Public Health Nutr. 2009;12(8):1133-1140. https://doi.org/10.1017/S1368980008003650

23. Tomlinson $M$, Swartz L, Kruger L-M, Gureje $O$. Manifestations of affective disturbance in sub-Saharan Africa: Key themes. J Affect Disord. 2007;102(1-3): 191-198. https://doi.org/10.1016/j.jad.2006.09.029

24. Hamad R, Fernald LCH, Karlan DS, Zinman J. Social and economic correlates of depressive symptoms and perceived stress in South African adults. J Epidemiol Community Health. 2008;62(6):538-544. https://doi.org/10.1136/jech.2007.066191

25. Paul KI, Moser K. Unemployment impairs mental health: Meta-analyses. J Vocat Behav. 2009;74(3):264-282. https://doi.org/10.1016/j.jvb.2009.01.001

26. McKee-Ryan F, Song Z, Wanberg CR, Kinicki AJ. Psychological and physical wellbeing during unemployment: A meta-analytic study. J Appl Psychol. 2005;90(1):53. https://doi.org/10.1037/0021-9010.90.1.53

27. Stankunas M, Kalediene R, Starkuviene S, Kapustinskiene V. Duration of unemployment and depression: A cross-sectional survey in Lithuania. BMC Public Health. 2006;6(1):174. https://doi.org/10.1186/1471-2458-6-174

28. McGee RE, Thompson NJ. Peer reviewed: Unemployment and depression among emerging adults in 12 states, behavioral risk factor surveillance system, 2010. Prev Chronic Dis. 2015;12:140451. https://doi.org/10.5888/pcd12.140451

29. S.A. Census South Africa. Available from http://census2011.adrianfrith.com/ place/599 
30. Van der Linden M, Knevel R, Huizinga T, van der Helm-Van Mil AM. Classification of rheumatoid arthritis: comparison of the 1987 American College of Rheumatology criteria and the 2010 American College of Rheumatology/ Rheumatology criteria and the 2010 American College of Rheumatology/ European League Against Rheuma
https://doi.org/10.1002/art.30100

31. Aletaha D, Neogi T, Silman AJ, et al. 2010 rheumatoid arthritis classification criteria: An American College of Rheumatology/European League Against criteria: An American College of Rheumatology/European League Against
Rheumatism collaborative initiative. Ann Rheum Dis. 2010;69(9):1580-1588. Rheumatism collaborative initiative. Ann
https://doi.org/10.1136/ard.2010.138461

32. Orpana HM, Berthelot JM, Kaplan MS, Feeny DH, McFarland B, Ross NA. BMI and mortality: Results from a national longitudinal study of Canadian adults. Obesity. 2010;18(1):214-218. https://doi.org/10.1038/oby.2009.191

33. Hazes JMW. Determinants of physical function in rheumatoid arthritis: Association with the disease process. Rheumatology (Oxford, England). 2003;42(Suppl 2):ii17-ii21. https://doi.org/10.1093/rheumatology/keg328

34. Bruce B, Fries JF. The Stanford Health Assessment Questionnaire: A review of its history, issues, progress, and documentation. J Rheumatol. 2003;30(1):167-178.

35. Benitha R, Tikly M. Functional disability and health-related quality of life in South Africans with rheumatoid arthritis and systemic lupus erythematosus. Clin Rheumatol. 2007;26(1):24-29. https://doi.org/10.1007/s10067-006-0215-4

36. Hodkinson B, Musenge E, Ally M, Meyer PWA, Anderson R, Tikly M. Functional disability and health-related quality of life in South Africans with early rheumatoid arthritis. Scand J Rheumatol. 2012:41(5):366-374. https://doi.org/10.3109/0300 9742.2012.676065

37. Prevoo ML, Van't Hof MA, Kuper HH, Van Leeuwen MA, Van de Putte LB, Van Rie PL. Modified disease activity scores that include twenty-eight-joint counts. Development and validation in a prospective longitudinal study of patients with rheumatoid arthritis. Arth Rheum. 1995;38(1):44-48. https://doi.org/10.1002/ rheumatoid arth

38. Smolen JS, Breedveld FC, Schiff $\mathrm{MH}$, et al. A simplified disease activity index for rheumatoid arthritis for use in clinical practice. Rheumatology (Oxford, England). rheumatoid arthritis for use in clinical practice. Rheumatology (Oxford
2003;42(2):244-257. https://doi.org/10.1093/rheumatology/keg072

39. Hodkinson B, Van Duuren E, Pettipher C, Kalla A. South African recommendations for the management of rheumatoid arthritis: An algorithm for the standard of care in 2013. S Afr Med J = Suid-Afrikaanse tydskrif vir geneeskunde. 2013;103(8 Pt 2):576-585. https://doi.org/10.7196/SAMJ.7047

40. Hodkinson B, Musenge E, Ally M, Meyer PWA, Anderson R, Tikly M. Response to traditional disease-modifying anti-rheumatic drugs in indigent South Africans with early rheumatoid arthritis. Clin Rheumatol. 2012;31(4):613-619. https://doi. org/10.1007/s10067-011-1900-5

41. Bhana A, Rathod SD, Selohilwe O, Kathree T, Petersen I. The validity of the Patien Health Questionnaire for screening depression in chronic care patients in primary health care in South Africa. BMC Psychiatry. 2015;15(1):1-9. https://doi. org/10.1186/s12888-015-0503-0

42. Cholera R, Gaynes B, Pence B, et al. Validity of the patient health questionnaire- 9 to screen for depression in a high-HIV burden primary healthcare clinic in Johannesburg, South Africa. J Affect Disord. 2014;167:160-166. https://doi. org/10.1016/j.jad.2014.06.003
43. Webb P, Coates J, Frongillo EA, Rogers BL, Swindale A, Bilinsky P. Measuring household food insecurity: Why it's so important and yet so difficult to do. J Nutr. 2006;136(5):1404S-1408S. https://doi.org/10.1093/jn/136.5.1404S

44. Oketch JA, Paterson M, Maunder EW, Rollins NC. Too little, too late: Comparison of nutritional status and quality of life of nutrition care and support recipient and non-recipients among HIV-positive adults in KwaZulu-Natal, South Africa. Health Policy. 2011;99(3):267-276. https://doi.org/10.1016/j.healthpol.2010.08.018

45. Gordon N, Godfrey E, Aber JL, Richter L, Group SR. Exploring patterns of receipt of cash grants, health care, and education among 7-10 year old children in KwaZuluNatal, South Africa. Child Youth Serv Rev. 2017;78:177-188. https://doi. org/10.1016/j.childyouth.2017.05.004

46. Gibbs A, Carpenter B, Crankshaw T, et al. Prevalence and factors associated with recent intimate partner violence and relationships between disability and depression in post-partum women in one clinic in eThekwini Municipality, South Africa. PLoS One. 2017:12(7):e0181236. https://doi.org/10.1371/journal.pone. 0181236

47. Herman AA, Stein DJ, Seedat S, Heeringa SG, Moomal H, Williams DR. The South African Stress and Health (SASH) study: 12-month and lifetime prevalence of common mental disorders. S Afr Med J. 2009;99(5):1-6.

48. Fu X, Li Z-J, Yang C-J, et al. The prevalence of depression in rheumatoid arthritis in China: A systematic review. Oncotarget. 2017;8(32):53623. https://doi. org/10.18632/oncotarget.17323

49. Jefferis BJ, Nazareth I, Marston L, et al. Associations between unemployment and major depressive disorder: Evidence from an international, prospective study (the predict cohort). Soc Sci Med. 2011;73(11):1627-1634. https://doi.org/10.1016/j. socscimed.2011.09.029

50. Jacob K, Sharan P, Mirza I, et al. Mental health systems in countries: Where are we now? Lancet. 2007;370(9592):1061-1077. https://doi.org/10.1016/S0140 6736(07)61241-0

51. Mesbah SF, Sulaiman N, Shariff ZM, Ibrahim Z. Does food insecurity contribute towards depression? A cross-sectional study among the urban elderly in Malaysia. Int J Environ Res Public Health. 2020;17(9):3118. https://doi.org/10.3390/ijerph17093118

52. Ward WL, Swindle TM, Kyzer AL, Edge N, Sumrall J, Whiteside-Mansell L. Maternal depression: relationship to food insecurity and preschooler fruit/vegetable consumption. Int J Environ Res Public Health. 2019:17(1):123. https://doi. org/10.3390/ijerph17010123

53. Mazure CM. Life stressors as risk factors in depression. Clin Psychol Sci Prac. 1998;5(3):291-313. https://doi.org/10.1111/j.1468-2850.1998.tb00151.x

54. Betancur MN, Lins L, Oliveira IRd, Brites C. Quality of life, anxiety and depression in patients with HIV/AIDS who present poor adherence to antiretroviral therapy: A cross-sectional study in Salvador, Brazil. Braz J Infect Dis. 2017;21(5):507-514. https://doi.org/10.1016/j.bjid.2017.04.004

55. Ji J, Zhang L, Zhang Q, et al. Functional disability associated with disease and quality-of-life parameters in Chinese patients with rheumatoid arthritis. Health Qual Life Outcomes. 2017;15(1):89. https://doi.org/10.1186/s12955-017-0659-z

56. Masood A, Salim B, Nasim A, Khalid Z, Afzal A. Are we missing the diagnosis of depression in patients with rheumatoid arthritis at a tertiary care facility? Pak Med Sci. 2017;33(2):300-305. Presse Med (Paris, France: 1983). 2012;41(5):e220e225. https://doi.org/10.12669/pjms.332.11856 